\title{
Selecting white clover (Trifolium repens L.) for sheep and cattle grazing environments
}

\section{Zulfi Jahufer $^{1}$, John Ford ${ }^{1}$, John Caradus ${ }^{2}$ and Derek Woodfield ${ }^{1}$}

${ }^{1}$ AgResearch Grasslands, Private Bag 11008, Palmerston North, New Zealand

${ }^{2}$ Fonterra Cooperative Ltd, PO Box 20261, Te Rapa, Hamilton, New Zealand

Abstract. Adaptation to different grazing systems is an important attribute in white clover breeding. A set of 41 white clover breeding lines and nine commercial cultivars were evaluated under two grazing systems, sheep and cattle, in Manawatu. The objective was to identify lines with either specific or broad adaptation to these two different grazing systems. The trials were established in late autumn 1997 and completed in autumn 2000. Visual scores of clover yield for spring, summer, autumn and winter of year 2 and spring, summer and autumn of year 3 were analysed. There was significant $(P<0.05)$ genotypic variation among lines and cultivars for yield across all seasons within each grazing system. Variance component analysis across all seasons and grazing treatments, indicated significant $(P<0.05)$ genotypic variation among the lines and cultivars, and also significant $(P<0.05)$ genotype-by-grazing system interaction. There was a lack of genetic correlation between the sheep and dairy grazing treatments. Breeding lines with specific adaptation to the sheep and dairy grazing systems were identified. Also, there were breeding lines with superior broad adaptation across the two grazing systems. All the breeding lines identified, were significantly $(P<0.05)$ superior in performance to the best performing commercial controls in each grazing system, indicating successful achievement of genetic advance for specific and broad adaptation. These superior breeding lines were experimental synthetics developed using germplasm with New Zealand and European background.

\section{Introduction}

White clover makes a significant contribution as a forage legume to the feed base of sheep and cattle in New Zealand. The intensification in production that is occurring in New Zealand pastoral industries has placed increasing pressure on white clover (Woodfield et al. 2001).

Breeding and selection of new plant material for broad or specific adaptation is complex when confounded by genotype-by-environment (GE) interaction effects (Cooper and Byth 1996). Multi-site evaluation trials not only enhance identification of adapted material but also help identify limitations of current cultivars and identify new objectives for breeding (Byth 1981). Developing new white clover cultivars for different grazing systems is often complicated by varying biotic and abiotic factors as well as different grazing management practices used by farmers. This emphasises the importance of conducting multi-site evaluation trials to screen breeding lines across target environments.

Selection of white clover breeding lines with specific or broad adaptation to the different grazing systems is an important breeding objective. This paper reports on the evaluation of a set of 41 white clover breeding lines and nine commercial cultivars under two grazing systems, sheep and cattle, in Manawatu, to identify lines with either specific or broad adaptation to the two grazing systems. 


\section{Materials and methods}

The set of 41 white clover breeding lines and nine commercial cultivars were evaluated at two sites; one grazed by dairy cows at the Massy University dairy farm and the other grazed by sheep at AgResearch, Grasslands, Manawatu. At each site, the experimental layout was a randomized complete block design with six replicates. Each replicate consisted of $1 \mathrm{~m}$ rows of each line represented by 10 genotypes per line. At the Massey site, the white clover was planted into an established grass mix which included perennial ryegrass (the endophyte status of the grass was not known). At the Grasslands site, the white clover rows were established in a high endophyte perennial ryegrass sward. The trials were rotationally grazed; the dairy site was grazed with 21 to 27 day rotations and the sheep grazed site was managed on a 6 week grazing rotation. Visual scoring (1 low to 10 high) of herbage production was carried out during the middle of each season just before grazing. The sward was topped after each grazing. The trial was established in late autumn 1997 and completed in autumn 2000.

Herbage production data were analysed using the variance component analysis procedure, REML, in GenStat 7.1 (2003). Variance component analysis was conducted within and across seasons in years 2 and 3 for each site, and also across all seasons and the two sites, using random effects linear models. Lack of genetic correlation among sites $\left(\mathrm{L}_{\mathrm{c}}\right)$ and heterogeneity of genotypic variance $(\mathrm{V})$ were calculated from the line-bysite interaction variance component (Cooper and DeLacy 1994).

\section{Results and discussion}

Results from analysis of herbage production scores within individual seasons in years 2 and 3 , from both the dairy and sheep grazing environment trials, indicate significant $(P<0.05)$ genotypic variation $\left(\boldsymbol{\sigma}_{\mathrm{g}}^{2}\right)$ among the lines and cultivars for the seasons; spring and summer of 1998, and autumn, winter and spring of 1999 (Table 1). Under sheep grazing, there was significant $(P<0.05)$ genotypic variation among the lines also in summer 1999 and autumn 2000. Analysis of herbage production across all seasons within each site indicated significant $(P<0.05)$ genotypic variation of $0.921 \pm 0.212$ and $1.466 \pm 0.313$ among the lines and cultivars at the cattle and sheep grazing sites, respectively.

Figures 1 and 2 show the top $30 \%$ breeding lines and nine commercial cultivars based on their mean herbage production scores across seasons in years 2 and 3 at the cattle grazing and sheep grazing sites. In each environment, a number of breeding lines were significantly $(P<0.05)$ superior in herbage production to the best performing commercial cultivar. These superior breeding lines were all experimental synthetic populations developed using a range of germplasm collected from within New Zealand and Europe.

Under cattle grazing, there were seven breeding lines that had significantly higher herbage production scores than the best performing commercial cultivar Kopu (Fig. 1). Line 38 had a 35\% higher herbage production in comparison to Kopu. Line 38 has subsequently been commercially released as cultivar Kopu II (Woodfield et al. 2001). In the sheep grazing environment, five breeding lines were significantly $(P<0.05)$ superior in herbage production scores in comparison to cultivar Prestige (Fig. 2). Line 3, released as cultivar Quest, had a 33\% improvement on cultivar Prestige. 
Table 1. Genotypic variance $\left(\boldsymbol{\sigma}_{\mathbf{g}}^{2}\right)$ components and standard errors (SE), from the analysis of seasonal herbage yield production scores in years 2 and 3 , from the 41 white clover breeding lines and 9 commercial cultivars evaluated under dairy cattle and sheep grazing.

\begin{tabular}{|c|c|c|c|c|c|}
\hline \multicolumn{3}{|c|}{ Dairy cattle grazing environment } & \multicolumn{3}{|c|}{ Sheep grazing environment } \\
\hline Seasons & $\sigma_{g}^{2}$ & $\mathrm{SE}$ & Seasons & $\sigma_{g}^{2}$ & $\mathrm{SE}$ \\
\hline Spring 98 & 1.757 & \pm 0.526 & Spring 98 & 1.871 & \pm 0.515 \\
\hline Summer 98 & 1.905 & \pm 0.672 & Summer 98 & 1.264 & \pm 0.373 \\
\hline Autumn 99 & 0.922 & \pm 0.329 & Autumn 99 & 1.269 & \pm 0.369 \\
\hline Winter 99 & 1.168 & \pm 0.335 & Winter 99 & 1.427 & \pm 0.403 \\
\hline Spring 99 & 0.636 & \pm 0.269 & Spring 99 & 1.126 & \pm 0.335 \\
\hline Summer 99 & 0.272 & \pm 0.211 & Summer 99 & 0.963 & \pm 0.310 \\
\hline Autumn 00 & 0.245 & \pm 0.233 & Autumn 00 & 1.139 & \pm 0.379 \\
\hline
\end{tabular}

Variance component analysis of herbage production scores across seasons and sites indicated significant $(P<0.05)$ genotypic $\left(\boldsymbol{\sigma}_{\mathbf{g}}^{2}\right)$ variation among the lines and commercial cultivars (Table 2$)$. There was also significant $(P<0.05)$ genotype-byseason $\left(\boldsymbol{\sigma}_{\mathbf{g s}}^{2}\right)$ interaction on average across both sites and genotype-by-environment $\left(\boldsymbol{\sigma}_{\text {ge }}^{2}\right)$ interaction. The relative change in the ranking of lines across the two sites is clearly indicated in figures 1 and 2. A large component of the genotype-byenvironment interaction was due to the lack of genetic correlation $\left(\mathbf{L}_{\mathbf{c}}\right)$ between the two sites (Table 2).

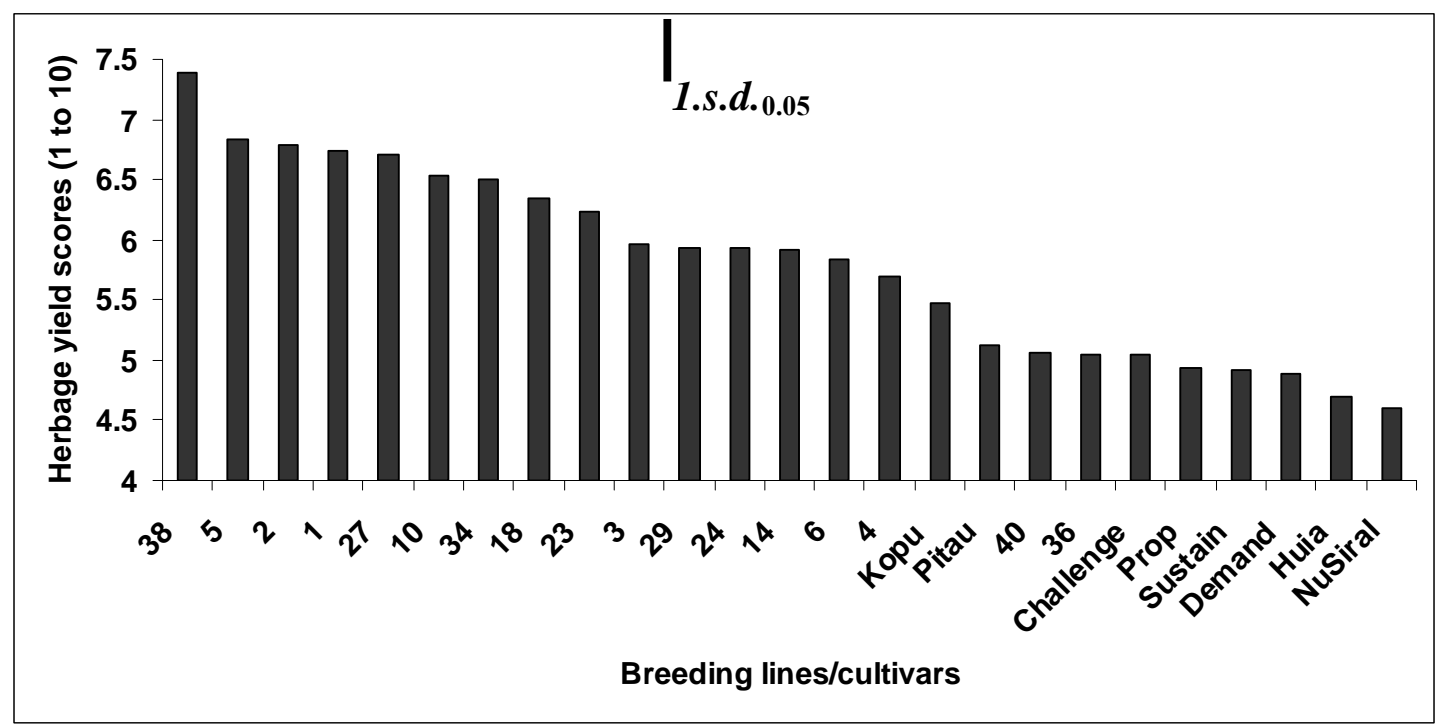

Fig. 1. Mean seasonal herbage yield scores across years 2 and 3, of the top $30 \%$ white clover breeding lines and nine commercial cultivars, evaluated under dairy cattle grazing. 


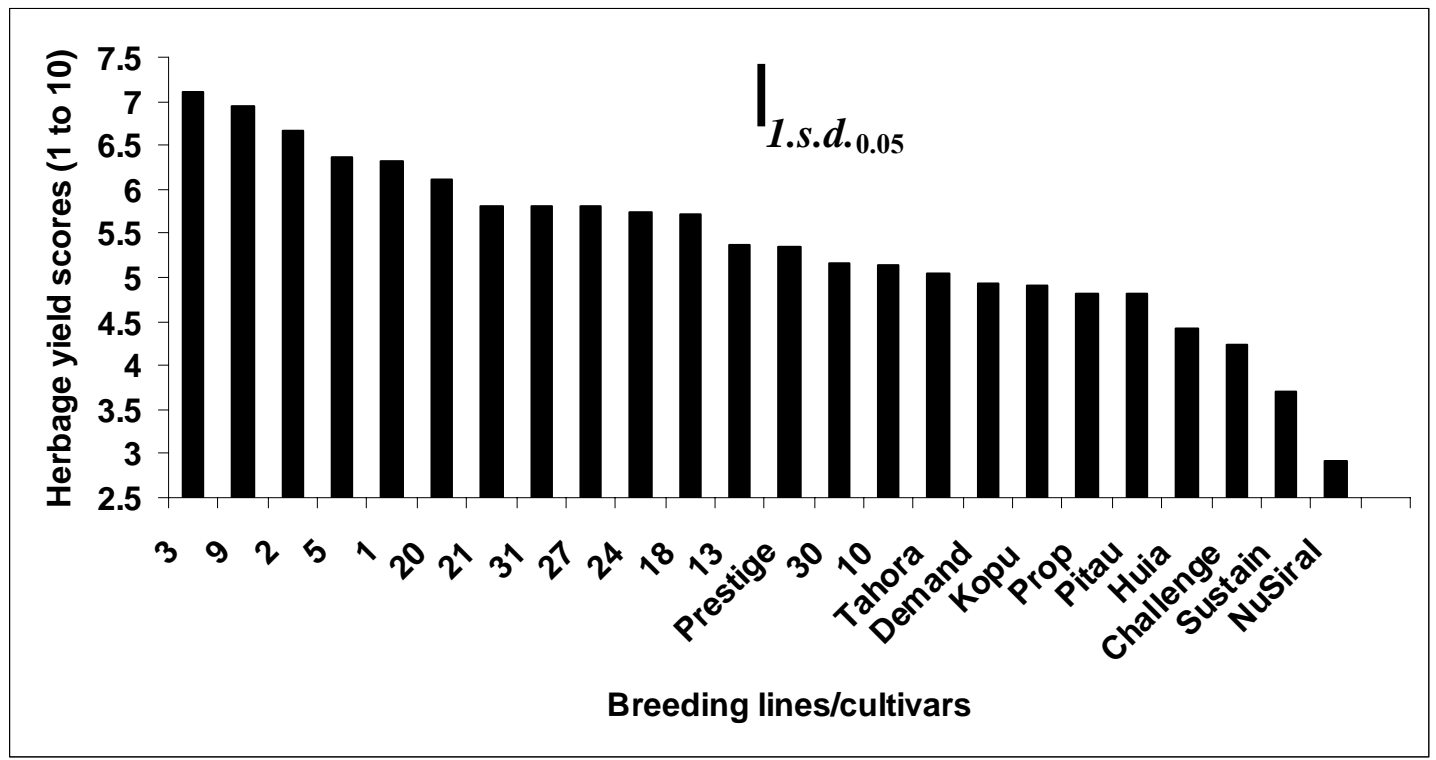

Fig. 2. Mean seasonal herbage yield scores across years 2 and 3, of the top 30\% white clover breeding lines and nine commercial cultivars, evaluated under sheep grazing.

A number of breeding lines had significantly $(P<0.05)$ superior seasonal herbage production scores in comparison to the commercial cultivars (Fig. 3). The line with the highest average herbage production score across both environments, line 2, was $30 \%$ superior to Kopu, the best performing commercial cultivar.

Table 2. Variance components and standard errors from the analysis of herbage yield production scores of the 41 white clover breeding lines and nine commercial cultivars, across seasons, years and two grazing environments (cattle and sheep). Variance components: $\boldsymbol{\sigma}_{\text {e }}$, variation between the two sites (grazing environments); $\boldsymbol{\sigma}^{2}$, variation among seasons; $\boldsymbol{\sigma}_{\mathbf{g}}^{\mathbf{2}}$, genotypic variation; $\boldsymbol{\sigma}_{\mathbf{g s}}^{\mathbf{2}}$, genotype-by-season interaction; $\boldsymbol{\sigma}_{\text {ge, }}^{\mathbf{2}}$ genotype-by-environment (site) interaction; $\boldsymbol{\sigma}_{\text {gse }}$, genotype-by-season-by-environment interaction. $\mathbf{L}_{\mathfrak{c}}$, lack of genetic correlation; $\mathbf{V}$, heterogeneity of genotypic variance.

\begin{tabular}{ccc}
\hline Source & Variance & SE \\
\hline$\sigma_{\mathrm{e}}^{2}$ & 0.159 & \pm 0.264 \\
$\sigma_{\mathrm{s}}^{2}$ & 0.282 & \pm 0.201 \\
$\sigma_{\mathrm{g}}^{2}$ & 0.691 & \pm 0.212 \\
$\sigma_{\mathrm{gs}}^{2}$ & 0.094 & \pm 0.046 \\
$\sigma_{\text {ge }}^{2}$ & 0.504 & \pm 0.122 \\
$\sigma_{\text {gse }}^{2}$ & 0 & \pm 0.059 \\
\hline $\mathrm{L}_{\mathrm{c}}=$ & 0.488 & \\
$\mathrm{~V}=$ & 0.016 & \\
\hline
\end{tabular}




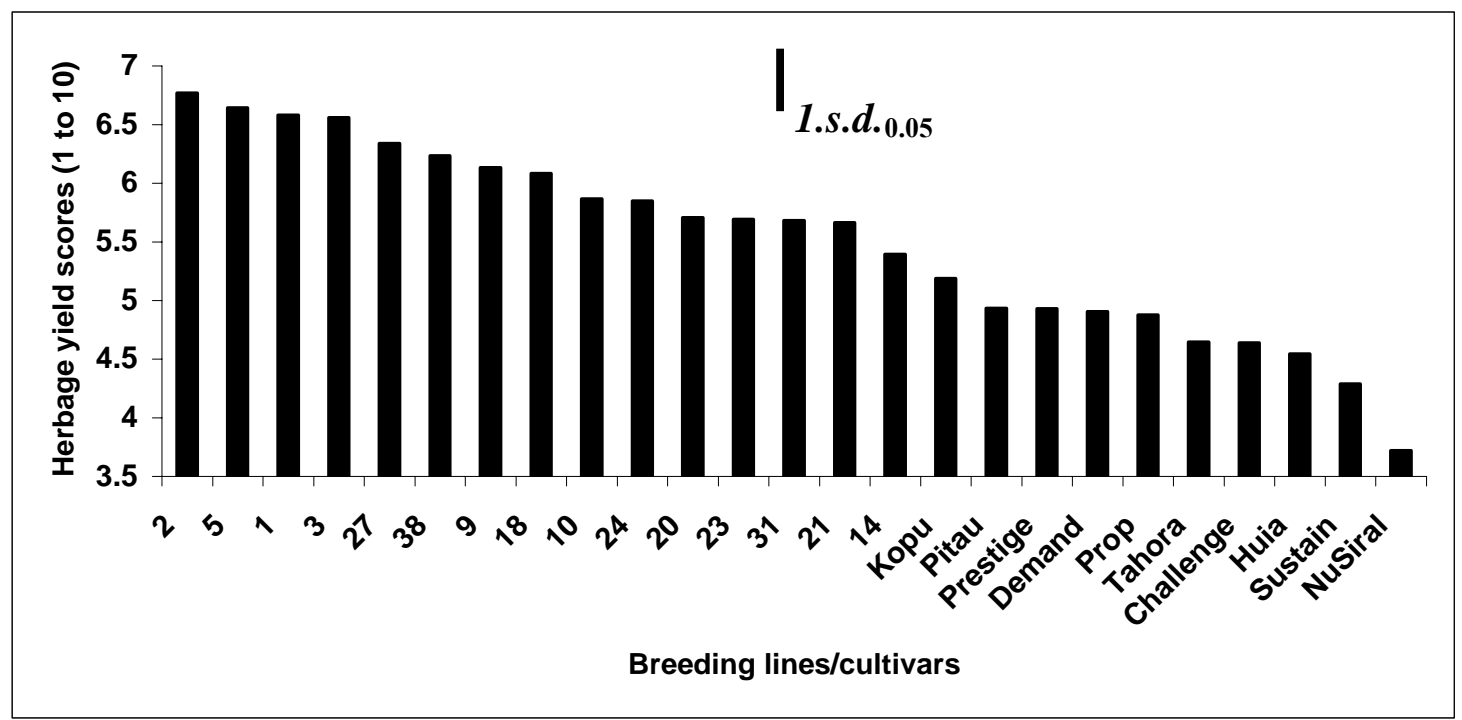

Fig. 3. Mean seasonal herbage yield scores across seasons, years and sites, of the top $30 \%$ white clover breeding lines and nine commercial cultivars, evaluated under sheep grazing.

Predicting repeatable plant performance across environments is a key to the successful development of new cultivars. Genotype-by-environment interactions are most problematic (they are also an opportunity!) to plant breeding programs when genotypes re-rank in their relative performance across environments (Cooper et al. 1993). The magnitude of the GE interaction components and lack of genetic correlation among the sheep and cattle grazing environments reported in our paper, provides a clear indication of the importance of multi-site testing, particularly where cultivars will be used in different grazing systems. Similar significant $(P<0.05)$ GE interactions were reported by Caradus (1993), for proportion of white clover in the sward, after evaluating 32 cultivars and elite breeding lines under sheep and cattle grazing environments. Jahufer et al. (1999) also reported significant GE interactions in white clover for summer herbage yield.

A key objective of the AgResearch white clover breeding program is to continue to identify and capture genetic gain that provides the basis for superior specific and broad adaptation of breeding populations relative to commercial cultivars. In this study, a number of breeding lines were significantly $(P<0.05)$ superior in performance to the best performing commercial controls in each grazing system, indicating the opportunity for successful achievement of genetic advance for both specific and broad adaptation. This has resulted in the release of the cultivars Grasslands Kopu II (line 38) for dairy systems and Quest (line 3) for sheep systems. Other superior breeding lines identified are being further evaluated in multi-site trials across different environments, as well as used in the development of new elite breeding populations.

\section{References}

Byth DE (1981) Genotype $\times$ environment interaction and environmental adaptation in plant improvement - An overview. In 'Interpretation of Plant Response and Adaptation to Agricultural Environments'. (Eds DE Byth, VE Mungomery) pp. 211. (Australian Institute of Agricultural Science, Queensland Branch: Brisbane). 
Caradus JR (1993) White clover breeding line performance under sheep and cattle grazing. In 'Proceedings of the 10th Australian Plant Breeding Conference'. Gold Coast, Vol. II, pp. 35-36.

Cooper M, Byth DE (1996) Understanding plant adaptation to achieve systematic applied crop improvement - A fundamental challenge. In 'Plant Adaptation and Crop Improvement'. (Eds M Cooper, GL Hammer). pp. 5-23. (CAB International, Wallingford, UK).

Cooper M, DeLacy IH (1994) Relationships among analytical methods used to study genotypic variation and genotype-by-environment interaction in plant breeding multi-environment trials. Theoretical and Applied Genetics, 88, 561-72.

Cooper M, DeLacy IH, Eisemann RL (1993) Recent advances in the study of genotype $\times$ environment interactions and their application to plant breeding. In 'Proceedings of the 10th Australian Plant Breeding Conference'. Gold Coast, Vol. I, pp.116-131.

GenStat. (2003) GenStat for Windows. Release 7.1. Seventh Edition. VSN International Ltd., Oxford.

Jahufer MZZ, Cooper M, Bray RA, Ayres JF (1999) Evaluation of white clover (Trifolium repens L.) populations for summer moisture stress adaptation in Australia. Australian Journal of Agricultural Research 50, 561-574.

Woodfield DR, Clifford PTP, Cousins GR, Ford JL, Baird IJ, Miller JE, Woodward SL, Caradus JR (2001) Grasslands Kopu II and Crusader: New generation white clovers. Proceedings of the New Zealand Grassland Association 63, 103-108. 